\title{
Effects of Retinoic Acid on Airspace Development and Lung Collagen in Hyperoxia-Exposed Newborn Rats
}

\author{
KATHLEEN A. VENESS-MEEHAN, FRANK G. BOTTONE, JR., AND ALAN D. STILES \\ Department of Pediatrics, Division of Neonatal-Perinatal Medicine, The University of North Carolina at \\ Chapel Hill, Chapel Hill, North Carolina, U.S.A.
}

\begin{abstract}
ABST
Impaired septal formation and decreased alveolarization are
often caused by hyperoxic injury to the developing lung and are
characteristic features of bronchopulmonary dysplasia. Dexa-
methasone, frequently administered to infants during oxygen
exposure, also inhibits septal formation in the newborn lung.
Vitamin A administration reduces the incidence of bronchopul-
monary dysplasia in vitamin A-deficient premature infants, and
retinoic acid improves alveolarization in newborn rats treated
with dexamethasone, indicating that retinoic acid may be useful
in preventing hyperoxia-induced impaired septation in broncho-
pulmonary dysplasia. To investigate whether treatment with
retinoic acid during exposure to hyperoxia would improve septal
formation, newborn rats exposed to $\geq 90 \%$ $\mathrm{O}_{2}$ from $\mathrm{d} 3$ of life to
$\mathrm{d} 14$ were treated with retinoic acid (d $3-13$ of life) and/or
dexamethasone (d $4-13$ of life). In contrast with the effects of
retinoic acid on dexamethasone-induced inhibition of alveolar-
ization, we found that retinoic acid did not improve septal
formation or decrease airspace size in animals exposed to hyper-
\end{abstract}
Prematurely born infants who require treatment with oxygen and mechanical ventilation for a significant time in the newborn period may develop BPD $(1,2)$. Attempts to limit the incidence and severity of BPD by lowering oxygen concentrations and by reducing barotrauma through early weaning from mechanical ventilation have been aided by the use of glucocorticoids in the postnatal period. Several studies have demonstrated the efficacy of dexamethasone in facilitating extubation in very low birth weight infants (3-6), but the use of steroids in premature infants has raised a host of concerns about effects on lung growth and development (7-9).

Massaro and others (8-10) have demonstrated inhibition of septal formation and alveolarization in newborn rats treated with dexamethasone between the ages of 4 and $14 \mathrm{~d}$, the period

Received May 17, 1999; accepted May 12, 2000.

Correspondence and reprint requests: Kathleen A. Veness-Meehan, M.D., Dept. of Pediatrics, CB\# 7596, 4th Floor UNC Hospitals, University of North Carolina at Chapel Hill, Chapel Hill, NC 27599-7596, U.S.A.

Supported by National Institutes of Health Grant HL 02996 (K.V.M.) and HL 56395 SCOR (K.V.M., A.D.S.). oxia alone or to hyperoxia plus dexamethasone. Retinoic acid did, however, increase collagen in airspace walls as demonstrated by staining and immunohistochemistry. There was no increase in procollagen mRNA by Northern hybridization analysis, indicating that retinoic acid-associated increases in lung collagen are likely due to posttranscriptional regulation. There was a trend toward increased survival in hyperoxia in animals treated with retinoic acid to the extent that combined therapy with retinoic acid and dexamethasone resulted in the greatest improvement in animal survival. These results suggest that although retinoic acid may be of benefit in hyperoxia-induced lung injury and may have important effects on lung matrix, it does not prevent impairment of septation or induce alveolar formation during exposure to hyperoxia. (Pediatr Res 48: 434-444, 2000)
Abbreviations
BPD, bronchopulmonary dysplasia
hpf, high-powered field

of most active alveolarization in the rat. Dexamethasone treatment resulted in fewer alveoli and a smaller gas-exchange surface area, similar to that seen in premature infants with BPD (11-13). In a subsequent study, Massaro and Massaro (14) demonstrated that the inhibition of alveolarization produced by dexamethasone treatment of newborn rats could be attenuated by the administration of retinoic acid. In addition to antagonizing some actions of dexamethasone, retinoic acid has been shown to play a role in lung development (15-18), and retinoids appear to participate in lung repair after hyperoxic injury $(19,20)$.

Although still controversial, evidence that the administration of vitamin A to vitamin A-deficient premature infants reduces the incidence of BPD suggests a protective or reparative role for retinol and its active metabolite retinoic acid during exposure to hyperoxia and mechanical ventilation (20-22). Similar to the actions of dexamethasone, hyperoxia also inhibits septal formation and affects alveolarization in the newborn lung (23, 24). It is possible, therefore, that retinoids improve outcomes in premature infants through effects on lung alveolarization. Be- 
cause dexamethasone is frequently administered to infants during oxygen exposure, it is important to determine whether agents proposed to improve alveolarization would offer benefit in the face of oxygen exposure and during treatment with both dexamethasone and oxygen. Furthermore, because retinoids appear to influence lung cell collagen gene expression $(19,25$, 26) and because collagen is involved in the pathogenesis of the pulmonary fibrosis seen in BPD, determination of the effects of retinoic acid treatment on lung collagen may also be important in evaluating its efficacy.

The purpose of the present study was to determine whether retinoic acid treatment would improve lung alveolarization and influence collagen gene expression in animals exposed to hyperoxia and dexamethasone from d 3 to 14 of life.

\section{METHODS}

Animals and treatments. Newborn Sprague-Dawley rats were injected intraperitoneally with diluent (cottonseed oil) or all trans-retinoic acid in diluent (500 $\mu \mathrm{g} / \mathrm{kg}$ ) (Sigma Chemical Co., St. Louis, MO, U.S.A.) beginning on postnatal d 3 (the day of birth was assigned to be postnatal d 0) and daily through postnatal d 13. All animals were maintained in either continuous flow $(4 \mathrm{~L} / \mathrm{min}) \geq 90 \% \mathrm{O}_{2}$ or room air. Beginning on postnatal $\mathrm{d} 4$ and continuing through postnatal $\mathrm{d} 13$, half of the diluent-treated rats and half of the retinoic acid-treated rats received dexamethasone $(0.25 \mu \mathrm{g} / \mathrm{d})$ (Elkins-Sinn, Cherry Hill, NJ, U.S.A.), whereas the other animals received sterile water. Oxygen or room air treatment was continued through postnatal d 13. Oxygen-exposed animals were maintained in Plexiglas chambers in which oxygen concentration was monitored twice daily, humidity maintained at greater than $80 \%$, and $\mathrm{CO}_{2}$ removed by soda lime absorption. Nursing mothers were rotated between litters in room air and hyperoxia every $24 \mathrm{~h}$. Room air controls were raised in the same room as hyperoxiaexposed animals and maintained under normal vivarium conditions. Five treatment groups were studied: 1 ) diluent/water/ room air, 2) diluent $/$ water $/ \mathrm{O}_{2}, 3$ ) retinoic acid/water/ $\mathrm{O}_{2}, 4$ ) diluent/dexamethasone $/ \mathrm{O}_{2}$, and 5) retinoic acid/dexamethasone $/ \mathrm{O}_{2}$. For the purpose of comparing this study with previous studies (14), three additional treatment groups were included in the morphologic measurements: 1) retinoic acid/water/room air, 2) diluent/dexamethasone/room air, and 3) retinoic acid/ dexamethasone/room air. At $14 \mathrm{~d}$ of age, animals from each group were killed by intraperitoneal injection of pentobarbital sodium $(200 \mathrm{mg} / \mathrm{kg})$. Lungs were either frozen in liquid nitrogen and then stored at $-80^{\circ} \mathrm{C}$ for RNA isolation or inflation fixed for volume measurements, quantification of airspace development, and collagen and elastin staining.

The present study was approved by the University of North Carolina at Chapel Hill Institutional Review Committee for Animal Studies.

Tissue preparation. For quantification of lung volumes, secondary crest formation, airspace areas, and collagen staining, the heart and lungs were exposed by thoracotomy, the abdominal aorta severed, and the inferior vena cava clamped. The lungs were perfused with $5 \mathrm{~mL}$ of ice-cold PBS via the right ventricle; the trachea was then cannulated and ice-cold
$10 \%$ buffered formalin instilled at a transpulmonary pressure of $20 \mathrm{~cm} \mathrm{H}_{2} \mathrm{O}$. After $15 \mathrm{~min}$, the trachea was ligated, the lungs were removed from the thorax, the heart and great vessels were removed, and fixation was continued in $10 \%$ buffered formalin overnight at $4^{\circ} \mathrm{C}$.

Lung volume measurements, quantitation of secondary crest formation, and airspace measurements. For lung volume measurements, the formalin-fixed lungs were equilibrated overnight in PBS at $4^{\circ} \mathrm{C}$ and lung volume measurements made in triplicate using the volume displacement technique (27).

For quantification of secondary crest formation, the lungs were dehydrated in 50 and $70 \%$ ethanol, and then the right caudal and left lobes of the lung were separated, placed together in cassettes, and embedded in paraffin. Fourmicrometer sections were cut from the approximate center of the paraffin block, mounted on Superfrost Plus slides (VWR Scientific, West Chester, PA, U.S.A.), and baked overnight at $55^{\circ} \mathrm{C}$. Slides were deparaffinized in a 3:1 mixture of Hemo-De (Fisher Scientific, St. Louis, MO, U.S.A.) and xylene and stained with Verhoff's stain for elastic fibers. Five nonoverlapping microscopic fields per lung lobe (10 fields per animal) were chosen on each slide and photographed. When choosing fields for analysis, care was taken to avoid underinflated areas and fields containing large vessels and airways. Secondary crests were identified by their characteristic structure: small ridges that contain elastic fibers and extend out from both sides of the primary alveolar septa. These ridges subsequently subdivide the lung saccules into alveoli (28). Crests were differentiated from alveolar septa by using the definition of an alveolus as a polygonal structure whose depth exceeds its diameter (29). The secondary crests were manually labeled and counted by a single observer who was blinded to the treatment group.

To quantify the effect of dexamethasone and retinoic acid on oxygen-induced changes in airspace size, we measured the areas of airspaces within $300 \mu \mathrm{m}$ of the pleura and calculated the volume densities of the gas-exchange airspace and the gas-exchange tissue. For airspace measurements, sections 4 $\mu \mathrm{m}$ thick were cut from the right middle lobe, mounted on slides, and stained with hematoxylin and eosin. Contiguous airspaces within $300 \mu \mathrm{m}$ of the pleura in each of six nonoverlapping fields (magnification $=\times 12.5$ ) were measured in lung sections chosen at random from three animals in each treatment group as previously described (30). Sections were viewed under bright field optics using an Olympus BH2 microscope (Olympus Corporation, Lake Success, NY, U.S.A.) equipped with a 10X lens. Images intended for morphometric analysis were acquired through a CCD camera (Panasonic, Secaucus, NJ, U.S.A.), digitized via Image-Pro Plus Image Processing System (Media Cybernetics, Silver Spring, MD, U.S.A.), and archived on a desktop computer. Area measurements were performed on a Power Macintosh 6100/60 using the public domain program NIH Image (version 1.6, National Institutes of Health, Bethesda, MD, U.S.A.). This program is available on the Internet at http://rsb.info.nih.gov/nih-image.

Volume densities were estimated using the program Stereology Toolbox (Morphometrix, Davis, CA, U.S.A.). Sections 2 $\mu \mathrm{m}$ thick were cut from the right middle lobe, mounted on 
slides, and stained with hematoxylin and eosin. Sections were viewed under bright field optics using an Olympus $\mathrm{BH} 2 \mathrm{mi}-$ croscope equipped with a $20 \mathrm{X}$ lens. Images were acquired through a CCD camera digitized via NIH Image and archived on a desktop computer. Volume densities were estimated using a Stereology Toolbox counting grid consisting of 125 points per field, counting the number of points falling on the compartment of interest (gas-exchange airspace, gas-exchange tissue) in 10 separate fields per animal (three animals per treatment group) and dividing by the total number of test points. Points falling on conducting airways and vessels were excluded.

Collagen staining. Collagen was visualized using $4-\mu \mathrm{m}$ sections of paraffin-embedded lung from the right caudal and left lobes of three animals from each of the five treatment groups, stained with Masson's trichrome stain for collagen. Paired slide sets were stained, photographed, and photoprocessed together to allow direct comparisons between photomicrographs.

Immunohistochemical analyses. Immunohistochemical analysis for type I and type III collagen was performed using rabbit anti-rat collagen type I and rabbit anti-rat collagen type III antibodies (Biodesign International, Kennebunk, ME, U.S.A.), $4-\mu \mathrm{m}$ sections of paraffin-embedded lung from three animals in each treatment group. Tissue sections were cut and mounted on Superfrost Plus slides, baked at $55^{\circ} \mathrm{C}$, and stored at room temperature until processed. The lung sections were deparaffinized, hydrated in a descending ethanol series, washed in PBS, and blocked overnight in $30 \%(\mathrm{wt} / \mathrm{vol})$ nonfat milk. Nonimmune rabbit serum and antisera preabsorbed with rat tail type I collagen were used as negative controls for immunostaining. Biotinylated goat anti-rabbit IgG (Jackson ImmunoResearch Lab Inc., West Grove, PA, U.S.A.) second antibody was used at 1:2000 dilution. Antibody-antigen complexes in tissue sections were visualized by the avidin-biotin-alkaline phosphatase method using the Vectastain ABC-AP kit (Vector Laboratories, Burlingame, CA, U.S.A.) and the substrate NBTBCIP (4-nitro blue tetrazolium chloride/5-bromo-chloro-3indolyl-phosphate) (Boehringer Mannheim, Indianapolis, IN, U.S.A.).

Paired slide sets for control and oxygen-exposed tissues were stained, photographed, and photoprocessed together to allow direct comparisons between photomicrographs.

RNA isolation and Northern hybridization analyses. Lungs from three to five 14-d-old animals in each of the five treatment groups were exposed by thoracotomy, removed and frozen immediately in liquid nitrogen, and then stored at $-80^{\circ} \mathrm{C}$. Total RNA was isolated from individual lung tissues using the Trizol reagent (GIBCO-BRL, Gaithersburg, MD, U.S.A.) and Trizol protocol. RNA concentrations were determined by spectrophotometric absorption at $260 \mathrm{~nm}$, and RNA was stored frozen at $-80^{\circ} \mathrm{C}$ until used for Northern analyses.

For Northern hybridization analyses, aliquots of $20 \mu \mathrm{g}$ total RNA were denatured in glyoxal, size-fractionated by electrophoresis through a $1.0 \%$ agarose gel, transferred to nylon membranes (Boehringer Mannheim, Indianapolis, IN, U.S.A.), and immobilized by UV cross-linking (UV Stratalinker by Stratagene, La Jolla, CA, U.S.A.) (31). Prehybridizations were performed in hybridization buffer [5X SSPE (20X SSPE $=3$ $\mathrm{M} \mathrm{NaCl}, 0.2 \mathrm{M}$ sodium phosphate, 0.02 M EDTA), 5X Denhardt's solution $(0.1 \%$ BSA, $0.1 \%$ polyvinylpyrrolidone, $0.1 \%$ Ficoll), $0.1 \%$ SDS, $50 \%$ formamide, $0.01 \%$ sonicated salmon sperm DNA] overnight at $42^{\circ} \mathrm{C}$. Hybridization was carried out in the same buffer containing $2 \times 10^{6} \mathrm{cpm}$ probe $/ \mathrm{mL}$ hybridization buffer at $42^{\circ} \mathrm{C}$ for $16-20 \mathrm{~h}$. After hybridization, membranes were washed at room temperature in successive changes of $2 \mathrm{X} \mathrm{SSPE}$ and at $65^{\circ} \mathrm{C}$ in $2 \mathrm{X}$ SSPE, $2.0 \%$ SDS. Hybridized membranes were subjected to autoradiography at $-80^{\circ} \mathrm{C}$ using Kodak X-AR or BioMax x-ray film (Eastman Kodak Co., Rochester, NY, U.S.A.) and intensifying screens. Changes in steady state mRNA abundance were determined by measuring the OD of hybridizing bands on the autoradiograms using the Image-Pro Plus Image Processing System (Media Cybernetics). Similar exposures of blots were used for densitometric analyses, and amounts of RNA loaded were normalized to the $18 \mathrm{~S}$ ribosomal band for each sample. Results for each experimental group are expressed as percent of diluent/water/room air (group 1) lung expression.

cDNA and probe preparation. For these studies, cDNA for the mouse $\alpha$-1 chain of type I procollagen [pro $\alpha 1(\mathrm{I})]$ was used. The pro $\alpha 1$ (I) cDNA corresponds to $321 \mathrm{bp}$ of the last exon of the mouse type I procollagen $\alpha-1$ chain. This cDNA was a generous gift from Benoit de Crombrugghe (M.D. Anderson Cancer Center, University of Texas, Houston, TX, U.S.A.). The cDNA was radiolabeled to high specific activity $\left(10^{8} \mathrm{cpm} / \mu \mathrm{g}\right.$ input DNA) by random hexamer labeling using the Random Primed DNA labeling kit (Boehringer Mannheim, Indianapolis, IN, U.S.A.) and $\alpha-\left[{ }^{32} \mathrm{P}\right] \mathrm{dCTP}$ (Amersham Pharmacia Biotech, Arlington Heights, IL, U.S.A.) (32).

Statistical methods. For survival, the number of animals surviving to the end of the treatment period was determined for each experimental group and then compared with diluent/ water/room air-treated animals using Fisher's exact test for groups with small numbers or $\chi^{2}$ contingency tables where permitted. For lung volumes, secondary crests, and airspace measurements, mean values were first calculated for each animal ( $n=3$ animals per group). For pro $\alpha 1(\mathrm{I})$, densitometric values for each animal ( $n=3$ animals per group) were normalized for loading differences and expressed as a percent of the value for diluent/water/room air-treated animals. For each parameter, experimental group means and standard errors were then determined using descriptive statistics. The effects of retinoic acid and dexamethasone treatment during exposure to hyperoxia were compared using 1-way ANOVA, and then significance was determined using Bonferroni's correction for multiple comparisons (33). To compare our results with those of Massaro and Massaro (14), volume density measurements were compared using ANOVA with Duncan's multiple-range test (33). Statistical analyses were performed on a desktop networked computer using the program SAS System for Windows, version 6.12 (SAS Institute, Cary, NC, U.S.A.).

\section{RESULTS}

Animal survival. Exposure to hyperoxia resulted in decreased survival with $50 \%$ of the animals in the diluent/ 
water/ $\mathrm{O}_{2}$ group $(n=20)$ surviving to the end of the treatment period versus $87 \%$ of the diluent/water/room air group $(n=$ 16) $(p<0.05)$ (Fig. 1). Treatment with retinoic acid $(n=15)$, dexamethasone $(n=16)$, or retinoic acid plus dexamethasone $(n=11)$ resulted in survival of animals exposed to hyperoxia of 62,56 , and $82 \%$, respectively.

Lung volumes. Lung volumes were not different between groups (Table 1). When lung volume measurements were corrected for animal body weight, although not statistically significant, the lung volume/g body weight of room-air control animals treated with diluent and with retinoic acid alone tended to be small relative to dexamethasone and oxygen-treated animals, suggesting that exposure to either dexamethasone or hyperoxia may affect body weight and somatic growth more than lung growth.

Secondary crest formation. Exposure to either dexamethasone or hyperoxia resulted in fewer secondary crests at $14 \mathrm{~d}$ of age $(\overline{\mathrm{x}}=43 \mathrm{crests} / \mathrm{hpf}$ in dexamethasone/room air group and $\overline{\mathrm{x}}=36$ crests/hpf in the $\mathrm{O}_{2}$-treated group versus $\overline{\mathrm{x}}=78$ crests/hpf in the control group, $p<0.05$ ) (Fig. 2). Retinoic acid treatment failed to overcome the effects of dexamethasone $(\overline{\mathrm{x}}=45 \mathrm{crests} / \mathrm{hpf}$ in the retinoic acid/dexamethasone-treated group) or hyperoxia $\left(\overline{\mathrm{x}}=38 \mathrm{crests} / \mathrm{hpf}\right.$ in the retinoic acid $/ \mathrm{O}_{2}-$ treated group) on crest formation. Treatment of oxygenexposed animals with dexamethasone resulted in further reduction in crest number $(\overline{\mathrm{x}}=24 \mathrm{crests} / \mathrm{hpf}$ in the dexamethasone/ $\mathrm{O}_{2}$-treated group) than either dexamethasone or oxygen treatment alone, and those effects were not reversed by retinoic acid treatment $(\overline{\mathrm{x}}=20 \mathrm{crests} / \mathrm{hpf}$ in the retinoic acid/ dexamethasone $/ \mathrm{O}_{2}$-treated group).

Airspace measurements. As shown in Figure 3, relative to air-exposed control animals, treatment of newborn animals with either dexamethasone (panels $C$ and $D$ ) or hyperoxia (panels $E-H$ ) resulted in marked differences in lung morphology.

To assess the effect of retinoic acid treatment on hyperoxiainduced changes in lung morphology both with and without dexamethasone treatment, measurements of airspace size, gas-

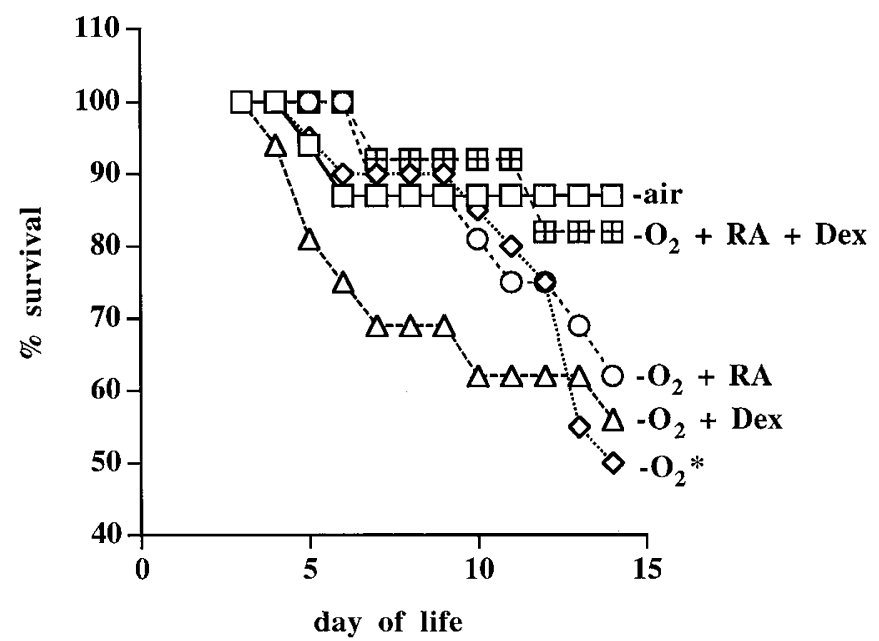

Figure 1. Animal survival in hyperoxia. Percent survival of animals in room air (air) $v s$ animals in hyperoxia $\left(\mathrm{O}_{2}\right)$, hyperoxia plus retinoic acid $\left(\mathrm{O}_{2}+R A\right)$, hyperoxia plus dexamethasone $\left(\mathrm{O}_{2}+\mathrm{Dex}\right)$, and hyperoxia plus retinoic acid plus dexamethasone $\left(\mathrm{O}_{2}+\mathrm{RA}+\mathrm{Dex}\right) .{ }^{*} p<0.05$ compared with air exposed.
Table 1. Lung volumes

\begin{tabular}{llll}
\hline \multicolumn{1}{c}{ Group } & \multicolumn{1}{c}{$\begin{array}{c}\text { Lung } \\
\text { volume* } \\
(\mu \mathrm{L})\end{array}$} & $\begin{array}{c}\text { Body } \\
\text { weight } \dagger(\mathrm{g})\end{array}$ & $\begin{array}{c}\text { Lung volume/g } \\
\text { body weight } \dagger \dagger \\
(\mu \mathrm{L} / \mathrm{g})\end{array}$ \\
\hline Diluent/water/air & $1343 \pm 151$ & $32.9 \pm 0.5$ & $40.8 \pm 4.3$ \\
Retinoic acid/water/air & $1318 \pm 339$ & $31.1 \pm 1.0$ & $41.8 \pm 9.8$ \\
Diluent/dexamethasone/air & $1353 \pm 76$ & $25.5 \pm 0.5$ & $53.1 \pm 3.6$ \\
Retinoic acid/dexamethasone/air & $1340 \pm 60$ & $24.7 \pm 1.4$ & $54.4 \pm 1.3$ \\
Diluent/water/O $\mathrm{O}_{2}$ & $1418 \pm 104$ & $31.1 \pm 2.3$ & $45.6 \pm 1.2$ \\
Retinoic acid/water/O $\mathrm{O}_{2}$ & $1301 \pm 129$ & $28.9 \pm 2.1$ & $44.9 \pm 2.6$ \\
Diluent/dexamethasone/ $\mathrm{O}_{2}$ & $1242 \pm 95$ & $27.6 \pm 1.0$ & $44.8 \pm 1.9$ \\
Retinoic acid/dexamethasone/ $\mathrm{O}_{2}$ & $1235 \pm 97$ & $23.2 \pm 3.1$ & $55.9 \pm 11.0$ \\
\hline
\end{tabular}

* Mean lung volumes as determined by the volume displacement technique \pm SEM.

$\dagger$ Mean body weight \pm SEM.

$\dagger \dagger$ Mean of lung volumes corrected for individual body weights \pm SEM.

exchange airspace volume density, and gas-exchange tissue volume density were made. For the purpose of comparing this study to that of Massaro and Massaro (14), these measurements were also performed on tissue from animals maintained in room air and treated with dexamethasone and retinoic acid. As shown in Figure 4, relative to airspace size in control animals, dexamethasone treatment of animals in room air resulted in a greater than 2 -fold increase in airspace size $(p<0.02)$. Treatment of dexamethasone-exposed room air animals with retinoic acid resulted in improved airspace development with smaller airspaces, similar to the retinoic acid-induced change in alveolarization reported by Massaro and Massaro (14). For animals in room air, dexamethasone increased the volume density of airspaces while decreasing the volume density of airspace wall tissue by $36 \%$ (Table 2). Retinoic acid alone had no effect on airspace volume density but increased airspace wall tissue by $34 \%$. Treatment of dexamethasone-exposed animals with retinoic acid resulted in a reduction in airspace volume density and an increase in wall tissue.

Exposure to hyperoxia resulted in an approximate 3-fold increase in mean airspace size compared with room airexposed animals $(p<0.02)$ and an overall increase of $19 \%$ in gas-exchange airspace (Table 3). Although not significant, treatment of oxygen-exposed animals with dexamethasone resulted in a trend toward an increase in airspace size and increased gas-exchange airspace. Treatment of oxygenexposed animals with retinoic acid alone resulted in a trend toward decreased airspace size. Treatment of oxygen-exposed animals with both dexamethasone and retinoic acid was no different with respect to mean airspace size than treatment with oxygen and dexamethasone alone. These results indicate that at the dose used, retinoic acid treatment does not alter the morphology of airspaces in developing animals exposed to hyperoxia.

Lung collagen staining. Staining for collagen fibers using Masson's trichrome stain demonstrated marked changes in lung collagen content with retinoic acid treatment. As shown in Figure 5, lung sections from room air controls and from animals exposed to oxygen show little collagen staining in alveolar walls. Retinoic acid treatment is associated with increased staining for collagen in both oxygen and oxygen plus dexamethasone-treated animals. Immunohistochemical stain- 
A
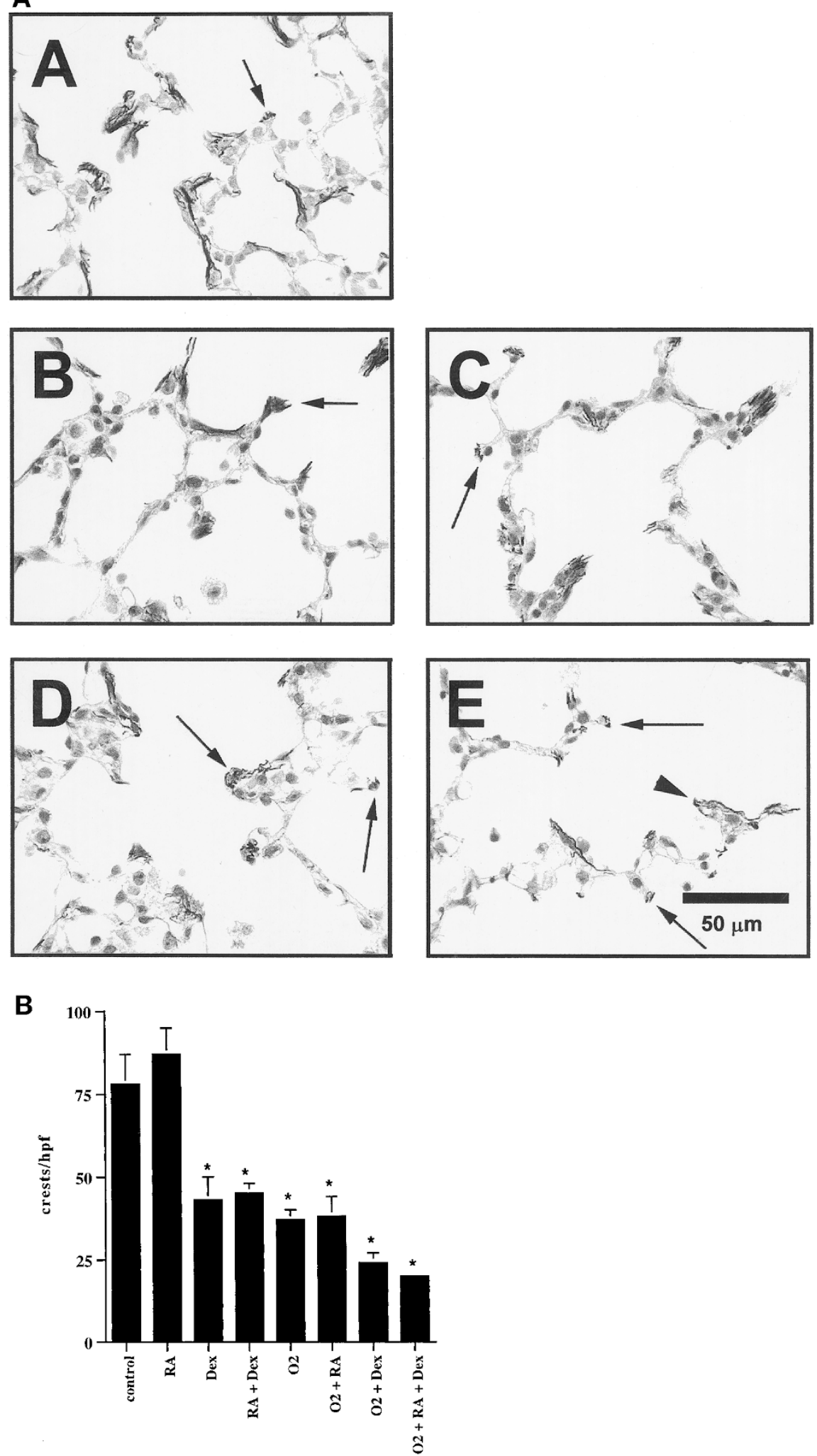

Figure 2. Secondary crest formation in room air-exposed newborn rats and in hyperoxia-exposed newborn rats treated with retinoic acid and dexamethasone. (A) Representative photomicrographs showing sections of rat lung stained for elastin from diluent/water/room air-treated $($ panel $A)$, diluent $/$ water/ $\mathrm{O}_{2}$-treated (panel B), retinoic acid/water $/ \mathrm{O}_{2}$-treated (panel C), diluent $/$ dexamethasone $/ \mathrm{O}_{2}$-treated (panel D), and retinoic acid $/$ dexamethasone $/ \mathrm{O}_{2}$-treated $($ panel E) animals. Secondary crests (arrows) are identified by characteristic structure and the presence of elastic fibers. Alveolar septa (arrowhead) are longer and define an alveolar space that is deeper than it is wide. Bar $=50 \mu \mathrm{m}$. (B) Number of secondary crests per hpf in diluent/water/room air-treated (control), retinoic acid/water/room air-treated $(R A)$, diluent/dexamethasone/room air-treated $(D e x)$, retinoic acid/dexamethasone/room air-treated $(R A+D e x)$, diluent $/$ water/ $\mathrm{O}_{2}$-treated $\left(\mathrm{O}_{2}\right)$, retinoic acid/water/ $\mathrm{O}_{2}$-treated $\left(\mathrm{O}_{2}+\mathrm{RA}\right)$, diluent/dexamethasone $/ \mathrm{O}_{2}$-treated $\left(\mathrm{O}_{2}+\right.$ Dex $)$, and retinoic acid/dexamethasone $/ \mathrm{O}_{2}$-treated $\left(\mathrm{O}_{2}+R A+D e x\right)$ animals. Values represent the means from each of five fields/lobe in lungs of three animals per treatment group $( \pm \mathrm{SEM}) .{ }^{*} p<0.05$ from 1 -way ANOVA with Bonferroni's correction comparing all treatment groups. 

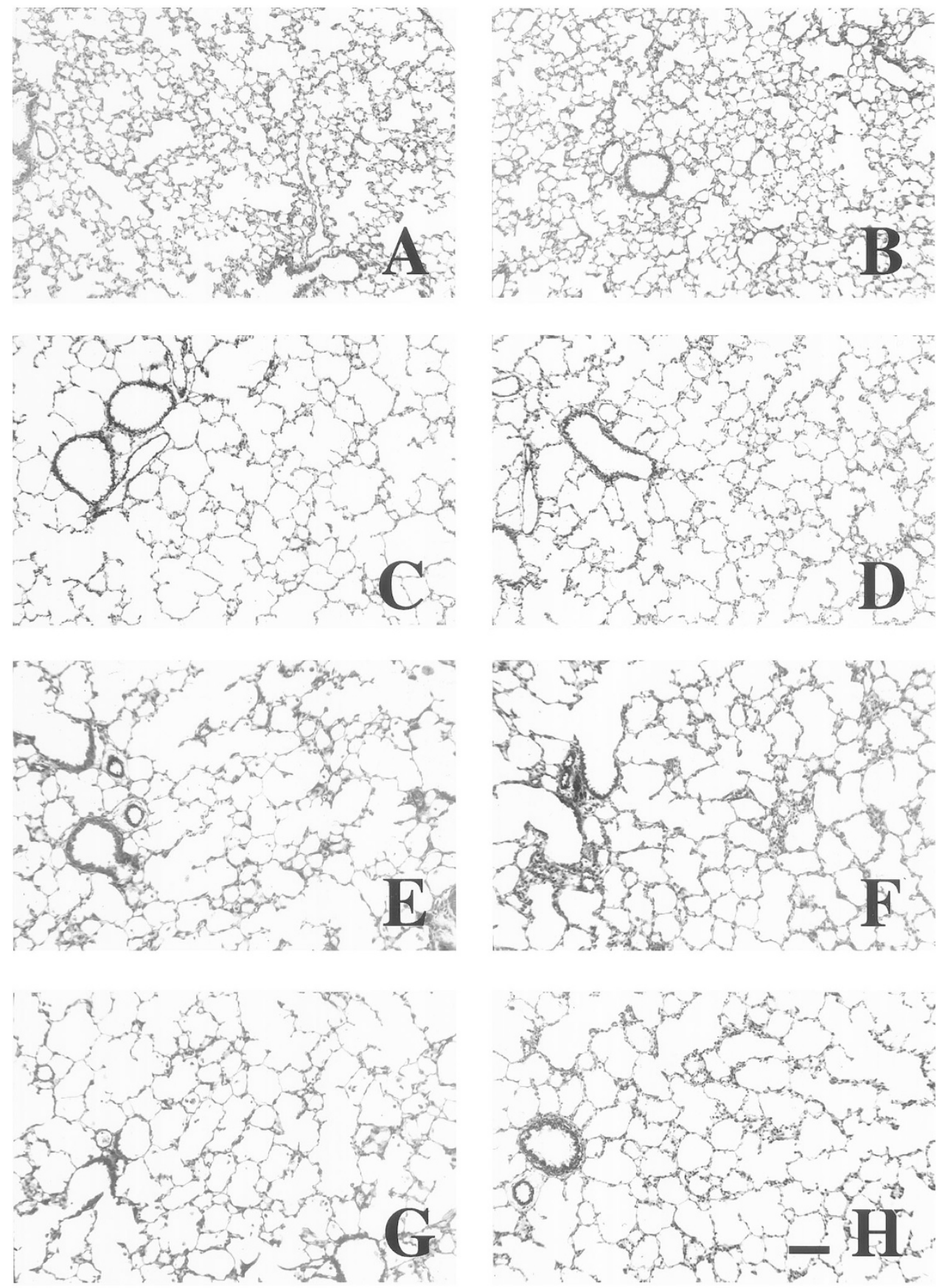

Figure 3. Lung morphology. Representative photomicrographs showing morphology of rat lung from diluent/water/room air-treated $(A)$, retinoic acid/water/ room air-treated $(B)$, diluent/dexamethasone/room air-treated $(C)$, retinoic acid/dexamethasone/room air-treated $(D)$, diluent/water/ $\mathrm{O}_{2}$-treated $(E)$, retinoic acid/water $/ \mathrm{O}_{2}$-treated $(F)$, diluent/dexamethasone $/ \mathrm{O}_{2}$-treated $(G)$, and retinoic acid/dexamethasone $/ \mathrm{O}_{2}$-treated $(H)$ animals. $B a r=100 \mu \mathrm{m}$.

ing for type I collagen (Fig. 6) confirmed the connective tissue staining results with an increase in type I collagen immunoreactivity in peribronchial and perivascular connective tissue and in airspace walls of lungs from animals treated with retinoic acid. Immunohistochemical staining using antisera to type I collagen, preabsorbed with rat tail type I collagen, showed no immunoreactivity. Immunohistochemical staining for type III collagen demonstrated type III collagen in all five groups with little change in immunoreactivity between treatment groups (results not shown).
Expression of type I collagen $\boldsymbol{m R N} A$. Figure $7 A$ shows a representative autoradiograph from the Northern hybridization analyses of RNA extracted from lung tissue of animals in each of the five treatment groups ( $n=3$ for each group). Figure $7 B$ is a graphic representation of the Northern hybridization analyses demonstrating a decrease in pro $\alpha 1(\mathrm{I})$ mRNA expression in lungs of animals exposed to hyperoxia $(p<0.05)$. Treatment of hyperoxia-exposed animals with either retinoic acid or dexamethasone was associated with a further decrease in pro $\alpha 1(\mathrm{I})$ mRNA expression $(p<0.05)$. Treatment of hyper- 


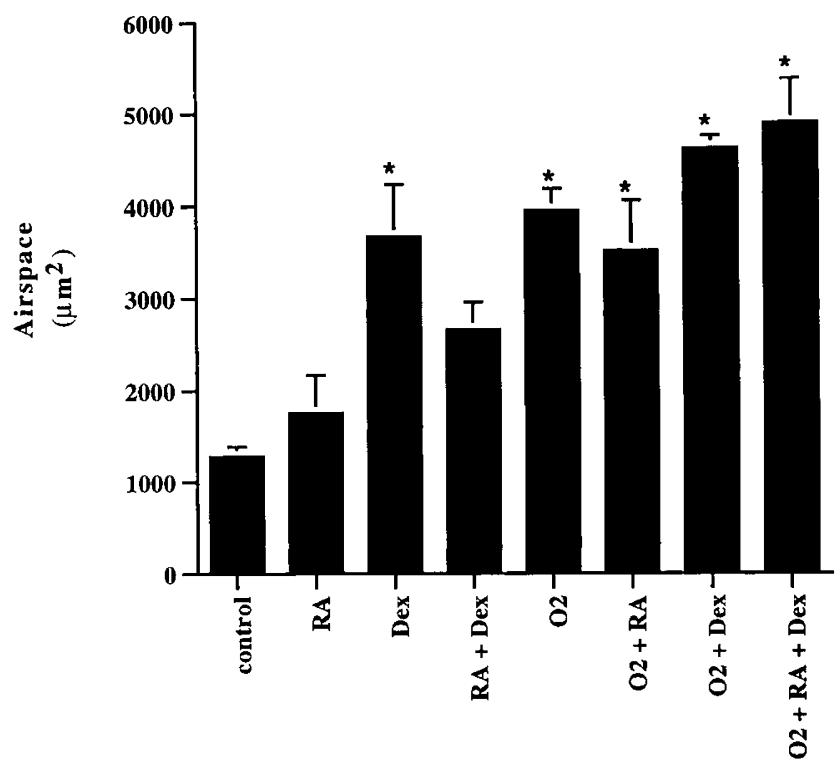

Figure 4. Airspace size. Mean airspace size measured within $300 \mu \mathrm{m}$ of the pleura in animals treated with diluent/water/room air (control), retinoic acid/ water/room air $(R A)$, diluent/dexamethasone/room air (Dex), retinoic acid/ dexamethasone/room air $(R A+D e x)$, diluent/water/ $\mathrm{O}_{2}\left(O_{2}\right)$, retinoic acid/ water $/ \mathrm{O}_{2}\left(\mathrm{O}_{2}+\mathrm{RA}\right)$, diluent/dexamethasone $/ \mathrm{O}_{2}\left(\mathrm{O}_{2}+\mathrm{Dex}\right)$, and retinoic acid/dexamethasone $/ \mathrm{O}_{2}\left(\mathrm{O}_{2}+\mathrm{RA}+\mathrm{Dex}\right)$. Values represent the mean airspace area measured in six fields per animal using three animals per treatment group $( \pm$ SEM). $\star p<0.02$ from 1-way ANOVA with Bonferroni's correction comparing all treatment groups.

Table 2. Volume density air exposed

\begin{tabular}{lcc}
\hline \multicolumn{1}{c}{ Group } & $\begin{array}{c}\text { Gas-exchange } \\
\text { airspace }\end{array}$ & $\begin{array}{c}\text { Gas-exchange } \\
\text { tissue }\end{array}$ \\
\hline 1 Diluent/water/air & $0.6451 \pm 0.025$ & $0.2320 \pm 0.004$ \\
2 Retinoic acid/water/air & $0.6747 \pm 0.012$ & $0.3120 \pm 0.013$ \\
3 Diluent/dexamethasone/air & $0.8395 \pm 0.010$ & $0.1504 \pm 0.012$ \\
4 Retinoic acid/dexamethasone/air & $0.7693 \pm 0.015$ & $0.2259 \pm 0.015$ \\
$p$ values for air groups & & \\
1 vs 2 & $\mathrm{NS}$ & $<0.05$ \\
1 vs 3 & $<0.05$ & $<0.05$ \\
1 vs 4 & $<0.05$ & $\mathrm{NS}$ \\
2 vs 3 & $<0.05$ & $<0.05$ \\
2 vs 4 & $<0.05$ & $<0.05$ \\
3 vs 4 & $<0.05$ & $<0.05$ \\
\hline
\end{tabular}

Mean values \pm SEM are given. Treatment with $\mathrm{O}_{2}$ was continuous from day of life 3 through 13 . Retinoic acid $(500 \mu \mathrm{g} / \mathrm{kg}$ ) or diluent was given daily from d 3 through 13. Dexamethasone $(0.25 \mu \mathrm{g} / \mathrm{d})$ or water was given daily from $\mathrm{d}$ 4 through 13. All animals were killed on d 14. NS, $p>0.05$.

$p$ values using Duncan's multiple-range test.

oxia-exposed animals with both retinoic acid and dexamethasone resulted in the greatest decrease in pro $\alpha 1(\mathrm{I})$ mRNA expression.

\section{DISCUSSION}

There is evidence from animal models that exposure of the developing lung to high concentrations of oxygen $(23,24)$ or to dexamethasone (12) inhibits alveolus formation and decreases lung surface area. Prematurely born infants with structurally immature lungs are often exposed to hyperoxia and sometimes to dexamethasone in the first days to weeks of life. Because of the potential for both hyperoxia and glucocorticoids to alter normal lung development, the identification of agents such as retinoic acid that may ameliorate those effects would be important to preserving the potential for normal pulmonary development.

Vitamin A (retinol) and its more active metabolite retinoic acid have long been recognized for their roles in vision and growth and more recently have been demonstrated to influence branching morphogenesis in lung $(16,34)$. Studies of lung development and genes involved in pattern formation indicate that retinoids may exert their primary influence through effects on genes responsible for lung morphogenesis $(15,16,34)$. It is also becoming clear that the effects of retinoids on lung are not limited to fetal development. Work by Massaro and Massaro (14) has shown that postnatal retinoic acid treatment increases the number of alveoli in developing rat lung and overcomes dexamethasone-induced inhibition of postnatal alveolarization.

Vitamin A also appears to be involved in protecting the lung from hyperoxic injury (35). Deficiency of vitamin A has been associated with the development of BPD $(21,36,37)$, and clinical trials have demonstrated that vitamin A supplementation of infants with decreased vitamin A stores may reduce the risk for developing BPD (20). Because retinoids may stimulate antioxidant defenses (38) and act as antioxidants (39), they may protect the lung from damage by oxygen free radicals generated through direct oxygen exposure and by inflammatory cells. All of these findings are consistent with clinical observations of the therapeutic benefits of vitamin A supplementation on postnatal lung but do not assess the effects of retinol on hyperoxia-induced changes in lung morphology such as those seen in BPD.

In the present study, we used a model that incorporates hyperoxic lung injury, dexamethasone administration, and retinoic acid supplementation. We found that treatment of newborn rats with retinoic acid during exposure to hyperoxia is associated with improved survival relative to animals exposed

Table 3. Volume density air control vs $\mathrm{O}_{2}$ exposed

\begin{tabular}{lcc}
\hline \multicolumn{1}{c}{ Group } & $\begin{array}{c}\text { Gas-exchange } \\
\text { airspace }\end{array}$ & $\begin{array}{c}\text { Gas-exchange } \\
\text { tissue }\end{array}$ \\
\hline 1 Diluent/water/air & $0.6451 \pm 0.025$ & $0.2320 \pm 0.004$ \\
2 Diluent/water/O $\mathrm{O}_{2}$ & $0.7677 \pm 0.025$ & $0.2213 \pm 0.019$ \\
3 Retinoic acid/water $/ \mathrm{O}_{2}$ & $0.7256 \pm 0.018$ & $0.2659 \pm 0.018$ \\
4 Diluent/dexamethasone/ $\mathrm{O}_{2}$ & $0.7725 \pm 0.027$ & $0.2168 \pm 0.028$ \\
5 Retinoic acid/dexamethasone/ $\mathrm{O}_{2}$ & $0.8096 \pm 0.022$ & $0.1832 \pm 0.023$ \\
$p$ values & & \\
1 vs 2 & $<0.05$ & $\mathrm{NS}$ \\
1 vs 3 & $<0.05$ & $\mathrm{NS}$ \\
1 vs 4 & $<0.05$ & $\mathrm{NS}$ \\
1 vs 5 & $<0.05$ & $\mathrm{NS}$ \\
2 vs 3 & $\mathrm{NS}$ & $\mathrm{NS}$ \\
2 vs 4 & $\mathrm{NS}$ & $\mathrm{NS}$ \\
2 vs 5 & $\mathrm{NS}$ & $\mathrm{NS}$ \\
3 vs 4 & $\mathrm{NS}$ & $\mathrm{NS}$ \\
3 vs 5 & $<0.05$ & $<0.05$ \\
4 vs 5 & $\mathrm{NS}$ & $\mathrm{NS}$ \\
\hline
\end{tabular}

Mean values \pm SEM are given. Treatment with $\mathrm{O}_{2}$ was continuous from day of life 3 through 13 . Retinoic acid $(500 \mu \mathrm{g} / \mathrm{kg})$ or diluent was given daily from d 3 through 13. Dexamethasone $(0.25 \mu \mathrm{g} / \mathrm{d})$ or water was given daily from $\mathrm{d}$ 4 through 13. All animals were killed on d 14. NS, $p>0.05$.

$p$ values using Duncan's multiple-range test. 

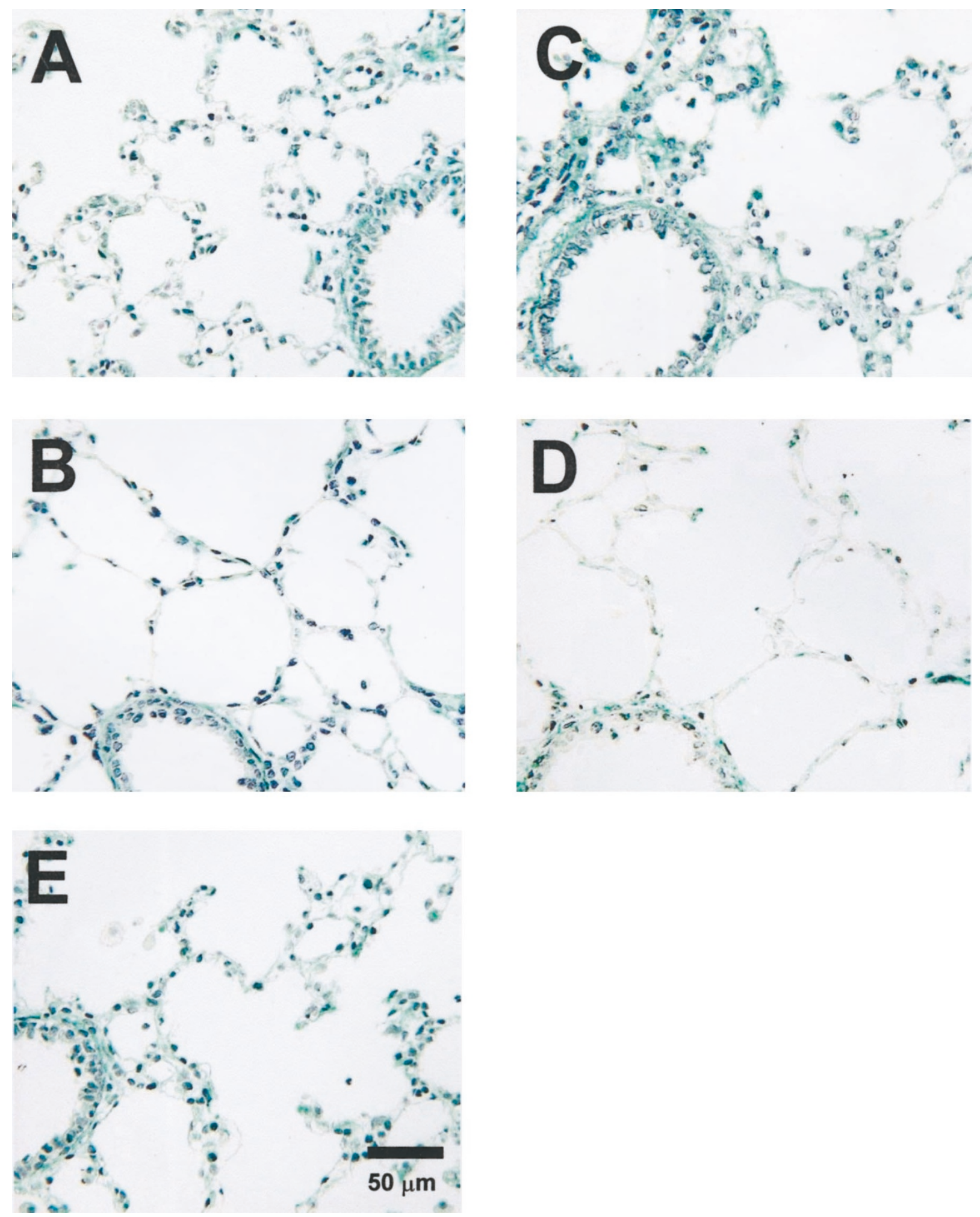

Figure 5. Collagen staining. Photomicrographs showing sections of rat lung stained for collagen (green staining) using Masson's trichrome stain. Diluent/ water/room air-treated (panel A), diluent $/$ water $/ \mathrm{O}_{2}$-treated (panel B), retinoic acid $/$ water $/ \mathrm{O}_{2}$-treated $\left(\right.$ panel $C$ ), diluent $/$ dexamethasone $/ \mathrm{O}_{2}$-treated $($ panel $D)$, and retinoic acid/dexamethasone $/ \mathrm{O}_{2}$-treated $($ panel $E$ ) animals. Stain: collagen $=$ green; nuclei $=$ blue/black. $B a r=50 \mu \mathrm{m}$.

to hyperoxia alone. Based on this result and the findings of Massaro et al. (14), we expected that retinoic acid treatment would attenuate hyperoxia-induced alterations in lung morphology in newborn animals. To examine this question, we evaluated secondary crest formation and measured lung volumes and airspace size.
Secondary crests are characteristic ridges growing out from the primary alveolar wall that will subsequently become secondary septa dividing the lung saccule into alveoli. Because the emergence of secondary crests occurs primarily during active alveolar formation, a process that occurs primarily in the first 2 wk of life in the rat (40) with some additional alveolar 


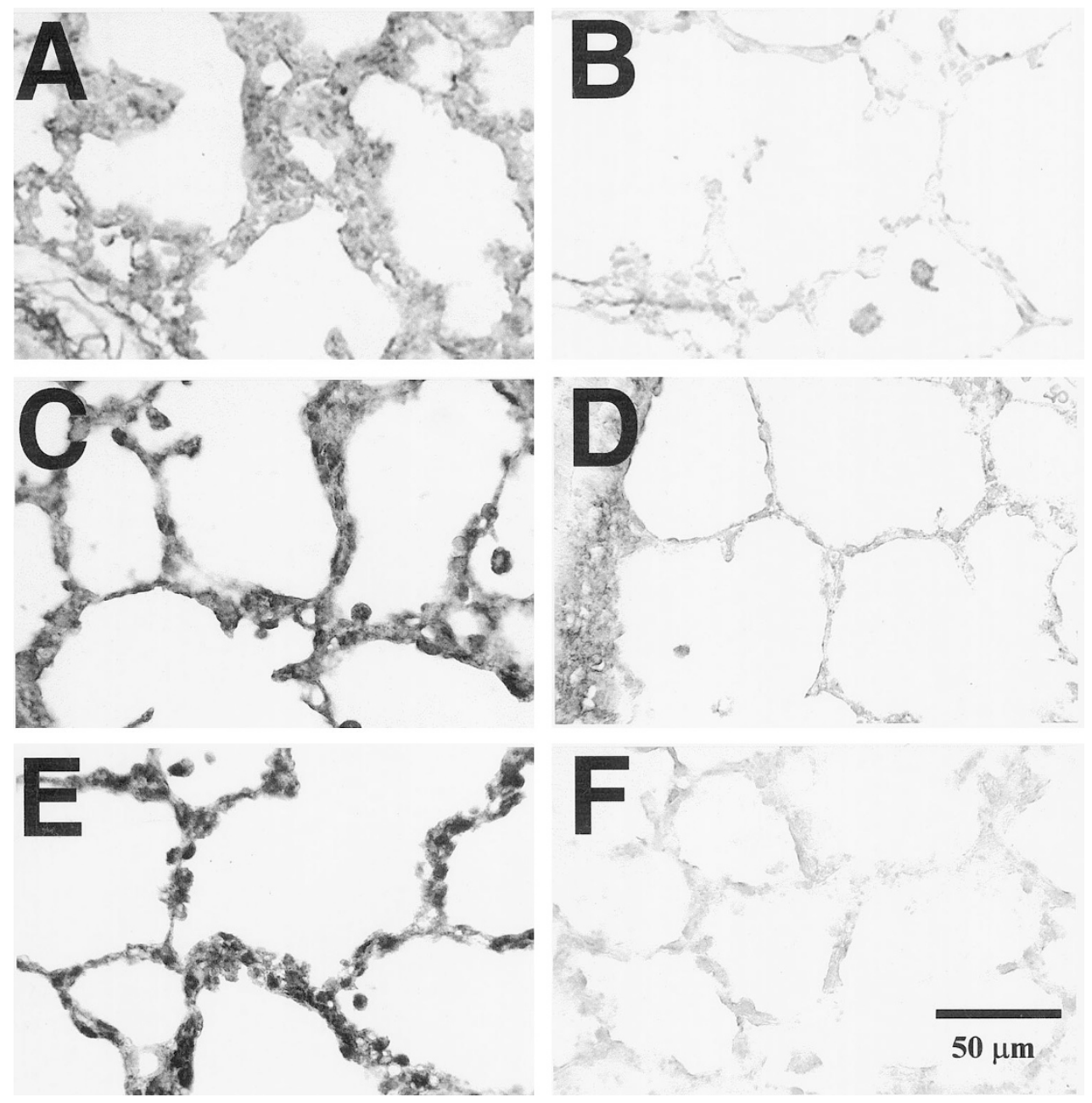

Figure 6. Immunostaining for type I collagen. Representative photomicrographs showing staining for type I collagen (black staining; no counterstain) in lung tissue from diluent/water/room air-treated $(A)$, diluent/water $/ \mathrm{O}_{2}$-treated $(B)$, retinoic acid $/$ water $/ \mathrm{O}_{2}$-treated $(C)$, diluent $/$ dexamethasone $/ \mathrm{O}_{2}$-treated $(D)$, retinoic acid/dexamethasone $/ \mathrm{O}_{2}$-treated $(E)$ animals. $(F)$ Shows lack of immunoreactivity in retinoic acid/dexamethasone/ $\mathrm{O}_{2}$-treated stained with preabsorbed antisera. Bar $=50 \mu \mathrm{m}$.

formation up to $60 \mathrm{~d}$ of life (41), changes in the number of secondary crests evident at $14 \mathrm{~d}$ of age may reflect changes in the rate of structural maturation. For example, a lung that has accelerated structural maturation may have fewer secondary crests because the crests are now full-length alveolar septa, indicating that septal formation has been completed. In that case, measurements of airspace size and lung volume are also necessary to assess changes in lung alveolarization. For these reasons, we evaluated the effects of retinoic acid treatment on lung volumes, airspace size, and tissue and airspace volume density in addition to secondary crest numbers.

We determined that there were no differences in mean lung volumes associated with exposure to hyperoxia or treatment with retinoic acid or dexamethasone. However, differences were found in airspace size. Both hyperoxia and dexamethasone administration are known to result in larger lung airspaces $(14,30)$. As expected, we found that both airspace areas and airspace volume density in animals maintained in room air were increased by dexamethasone and that treatment with retinoic acid reversed the dexamethasone effect, findings similar to those of Massaro et al (14). Similarly, in room airexposed animals, numbers of secondary crests were decreased by dexamethasone. Retinoic acid supplementation did not, however, reverse the dexamethasone effect on secondary crest number. In our studies of oxygen-exposed animals, retinoic acid was unable to alter airspace size or airspace volume density in the lungs of animals exposed to hyperoxia alone or exposed to hyperoxia and treated with dexamethasone. Similarly, numbers of secondary crests were decreased by hyperoxia, an effect that was not attenuated by retinoic acid supplementation. It should be noted that because of the difficulty in distinguishing between alveoli and alveolar ducts in oxygeninjured lung, these studies measured airspace area and did not differentiate between the two. Although this limits the ability to determine changes in alveolar size, it is likely to be more physiologically relevant to differences in gas-exchange surface area.

The mechanisms by which hyperoxia and dexamethasone affect alveolar size in the developing lung are unclear. It is possible that inhibition of septal formation may occur via different mechanisms with hyperoxia, accounting for the ability of retinoic acid to mitigate the effects of dexamethasone on alveolarization in animals in room air while providing little benefit to alveolar formation during exposure to hyperoxia. 


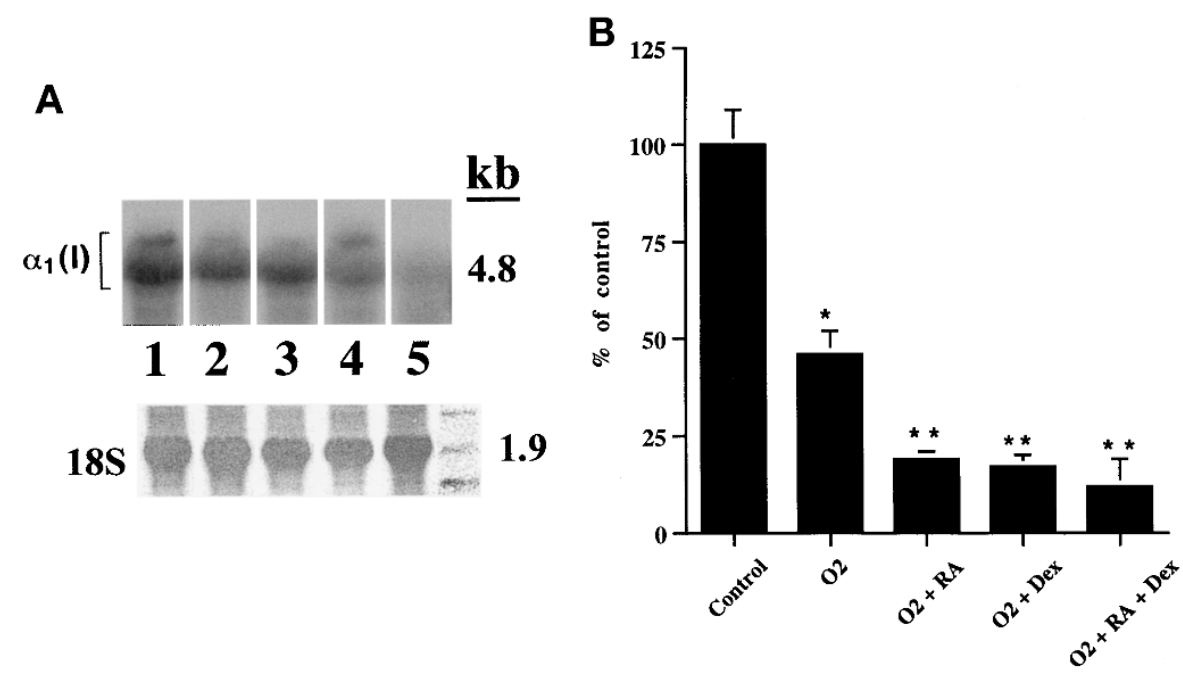

Figure 7. Type I collagen mRNA. (A) Representative autoradiograph from Northern hybridization analyses of RNA from diluent/water/room air-treated (lane 1), diluent/water $/ \mathrm{O}_{2}$-treated (lane 2), retinoic acid/water/ $\mathrm{O}_{2}$-treated (lane 3), diluent/dexamethasone $/ \mathrm{O}_{2}$-treated (lane 4), and retinoic acid/dexamethasone $/ \mathrm{O}_{2}$ treated (lane 5) animals hybridized with pro $\alpha 1(\mathrm{I})$ collagen cDNA. Lower panel: $18 \mathrm{~S}$ ribosomal RNA by methylene blue staining. (B) Quantitative changes in pro $\alpha 1$ (I) collagen mRNA expression by Northern hybridization analyses of total RNA from diluent/water/room air-treated (control), diluent/water/ $\mathrm{O}_{2}$-treated $\left(\mathrm{O}_{2}\right)$, retinoic acid/water $/ \mathrm{O}_{2}$-treated $\left(\mathrm{O}_{2}+R A\right)$, diluent/dexamethasone $/ \mathrm{O}_{2}$-treated $\left(\mathrm{O}_{2}+\right.$ Dex $)$, and retinoic acid $/$ dexamethasone $/ \mathrm{O}_{2}$-treated $\left(\mathrm{O}_{2}+R A+D e x\right)$ animals expressed as a percentage of diluent/water/room air (control) values. Hybridizing bands at $4.8 \mathrm{~kb}$ were quantified by OD measurement of autoradiographs, normalized to $18 \mathrm{~S}$ ribosomal bands, and expressed as the mean ( \pm SEM) of at least three animals. $\star v s$ control, $p<0.05$ from 1-way ANOVA with Bonferroni's correction comparing all treatment groups. $\star \star v s$ oxygen-exposed, $p<0.05$ from 1-way ANOVA with Bonferroni's correction comparing oxygen-treated groups.

Alternatively, it is possible that the dose of retinoic acid chosen for these studies was not optimal to ameliorate the effects of hyperoxia on lung alveolarization. In these studies, the dose and route of administration for both retinoic acid and dexamethasone were identical to those used by Massaro and Massaro (14) in which retinoic acid attenuated the reduction in alveolar number and body mass-specific surface area caused by dexamethasone administration. However, studies have shown that hyperoxia alone induces changes in lung retinoic acidbinding proteins and receptors as does treatment with dexamethasone (42), raising the possibility that the effective dose of retinoic acid may be different for animals exposed to hyperoxia.

The most prominent effect of retinoic acid treatment observed in these studies was the increased collagen staining in airspace walls of retinoic acid-treated oxygen-exposed rats. Most of the lung extracellular matrix is collagen, predominately types I and III with lesser amounts of types IV and V (43). We have previously shown that in adult rats, acute hyperoxic injury decreases expression of mRNA for both type I $[\operatorname{pro} \alpha 1(\mathrm{I})]$ and type III $[\operatorname{pro} \alpha 1(\mathrm{III})]$ collagen in lung but increases immunostaining for type I collagen, indicating that oxygen exposure may affect posttranscriptional events important to collagen mRNA translation or collagen degradation. In that same model, we demonstrated that retinol deficiency is associated with decreases in both type I procollagen [pro $\alpha 1$ (I)] mRNA and type I collagen immunoreactivity in lung (19). In contrast, the present study demonstrates decreases in both type I [pro $\alpha 1(\mathrm{I})]$ collagen mRNA and type I collagen immunoreactivity with chronic oxygen exposure alone. The differences in response to oxygen-induced injury between these two studies may be due to age-related differences in the newborn and adult response to injury, or it may be related to chronic versus acute injury. The present study also demonstrates further decreases in type I [pro $\alpha 1(\mathrm{I})]$ collagen mRNA with retinoic acid treatment alone and with retinoic acid in combination with dexamethasone. Staining for collagen fibers and immunohistochemical staining for type I collagen demonstrate increases in collagen content in the lungs of animals treated with retinoic acid during exposure to hyperoxia, suggesting that retinoic acid treatment may influence either pro $\alpha 1$ (I) mRNA translation or type I collagen degradation, both of which are important to the regulation of total lung collagen $(44,45)$.

The mechanisms by which retinoic acid alters lung collagen are unknown; however, the lung contains nuclear retinoic acid receptors $(42,46)$, nuclear ligand-activated enhancer proteins that bind to specific DNA sequences near the promoters of responsive genes and exert effects on transcription $(46,47)$. Although information concerning the genes activated by retinoic acid binding to the retinoic acid receptors is limited, retinoic acid has been demonstrated to alter gene expression of more than 300 gene products (48) including collagenase and tissue inhibitor of metalloproteinase (TIMP), a compound involved in the activation of collagenase $(49,50)$. It is plausible that changes in expression of collagen-degrading enzymes regulated by retinoic acid are major factors in alterations of total lung collagen and that increased lung collagen confers some benefit in lung function, resulting in greater survival in hyperoxia.

It should be noted that the period of oxygen exposure used for these studies encompassed the time during which most of alveolar development occurs in the rat lung. In contrast, human alveolar development spans at least the first 2 y of life. So although at the dose used for these studies it does not appear that retinoic acid treatment during exposure to prolonged hyperoxia will prevent impairment of septation or induce alveolar formation in the immature rat lung, caution is warranted in 
applying these observations to the treatment of newborn infants exposed to hyperoxia for periods of time that encompass much shorter developmental periods. In addition, changes in expression of growth factors, structural proteins, membrane receptors, and enzymes have been reported with both oxygen and retinoic acid treatment, emphasizing the complexity of the injury model and treatment responses to retinoic acid. Whether retinoic acid treatment after hyperoxic lung injury will induce or augment the formation of new alveoli and improve longterm pulmonary function in the developing lung is yet to be determined.

Acknowledgments. The authors thank Brian Brighton for his technical assistance and Dr. Marianna Henry for her assistance with lung volume measurements.

\section{REFERENCES}

1. Bancalari E, Gerhardt T 1986 Bronchopulmonary dysplasia. Pediatr Clin North Am 33:1-23

2. Abman SH, Groothius JR 1994 Pathophysiology and treatment of bronchopulmonary dysplasia: current issues. Pediatr Clin North Am 41:277-315

3. Collaborative Dexamethasone Trial Group 1991 Dexamethasone therapy in neonatal chronic lung disease: an international placebo-controlled trial. Pediatrics 88:421-428

4. Sanders RJ, Cox C, Phelps DL, Sinkin RA 1994 Two doses of early intravenous dexamethasone for the prevention of bronchopulmonary dysplasia in babies with respiratory distress syndrome. Pediatr Res 36:122-128

5. Hazinski TA 1993 Gene transfection of lung cells in vitro and in vivo. Annu Rev Physiol 55:181-207

6. Harkavy KL, Scanlon JW, Chowdhry PK, Grylack LJ 1989 Dexamethasone therapy for chronic lung disease in ventilator- and oxygen-dependent infants: a controlled trial. J Pediatr 115:979-983

7. Skinner AM, Battin M, Solimano A, Daaboul J, Kitson HF 1997 Growth and growth factors in premature infants receiving dexamethasone for bronchopulmonary dysplasia. Am J Perinatol 14:539-546

8. Sahebjami H, Domino M 1989 Effects of postnatal dexamethasone treatment on development of alveoli in adult rats. Exp Lung Res 15:961-973

9. Massaro D, Massaro GD 1986 Dexamethasone accelerates postnatal alveolar wall thinning and alters wall composition. Am J Physiol 251:R218-R224

10. Massaro D, Teich N, Maxwell S, Massaro GD, Whitney P 1985 Postnatal development of alveoli: regulation and evidence for a critical period in rats. J Clin Invest 76:1297-1305

11. Sobonya RE, Logvinoff MM, Taussig LM, Theriault A 1982 Morphometric analysis of the lung in prolonged bronchopulmonary dysplasia. Pediatr Res 16:969-972

12. Blanco LN, Frank L 1993 The formation of alveoli in rat lung during the third and fourth postnatal weeks: effect of hyperoxia, dexamethasone, and deferoxamine. Pediatr Res 34:334-340

13. Husain AN, Siddiqui NH, Stocker JT 1998 Pathology of arrested acinar development in postsurfactant bronchopulmonary dysplasia. Hum Pathol 29:710-717

14. Massaro GD, Massaro D 1996 Postnatal treatment with retinoic acid increases the number of pulmonary alveoli in rats. Am J Physiol 270:L305-L310

15. Bogue CW, Gross I, Vasavada H, Dynia DW, Wilson CM, Jacobs HC 1994 Identification of Hox genes in newborn lung and effects of gestational age and retinoic acid on their expression. Am J Physiol 266:L448-L454

16. Cardoso WV, Mitsialis SA, Brody JS, Williams MC 2071996 Retinoic acid alters the expression of pattern-related genes in the developing rat lung. Dev Dyn 47-59

17. Schuger L, Varani J, Mitra R, Gilbride K 1993 Retinoic acid stimulates mouse lung development by a mechanism involving epithelial-mesenchymal interaction and regulation of epidermal growth factor receptors. Dev Biol 159:462-473

18. Chytil F 1996 Retinoids in lung development. FASEB J 10:986-992

19. Veness-Meehan KA 1997 Effects of retinol deficiency and hyperoxia on collagen gene expression in rat lung. Exp Lung Res 23:569-581

20. Shenai JP, Kennedy KA, Chytil F, Stahlman MT 1987 Clinical trial of vitamin A supplementation in infants susceptible to bronchopulmonary dysplasia. J Pediatr 111:269-277
21. Pearson E, Bose C, Snidow T, Ransom L, Young T, Bose G, Stiles A 1992 Trial of vitamin A supplementation in very low birth weight infants at risk for bronchopulmonary dysplasia. J Pediatr 121:420-427

22. Tyson JE, Wright L, Oh W, Kennedy KA, Mele L, Ehrenkranz RA, Stoll BJ, Lemons JA, Stevenson DK, Bauer CR, Korones SB, Fanaroff AA 1999 Vitamin A supplementation for extremely-low-birth-weight infants. N Engl J Med 340:1962-1968

23. Veness-Meehan KA, Rhodes DN, Stiles AD 1994 Temporal and spatial expression of biglycan in chronic oxygen-induced lung injury. Am J Resp Cell Mol Biol 11:509516

24. Randell SH, Mercer RR, Young SL 1989 Postnatal growth of pulmonary acini and alveoli in normal and oxygen-exposed rats studied by serial section reconstructions. Am J Anat 186:55-68

25. Federspiel SJ, DiMari SJ, Guerry-Force ML, Haralson MA 1990 Extracellular matrix biosynthesis by cultured fetal rat lung epithelial cells. Lab Invest 63:455-466

26. Federspiel SJ, DiMari SJ, Howe AM, Guerry-Force ML, Haralson MA 1991 Extracellular matrix biosynthesis by cultured fetal rat lung epithelial cells. Lab Invest 65:441-450

27. Scherle W 1970 A simple method for volumetry of organs in quantitative stereology. Mikroskopie 26:57-60

28. Burri PH 1974 The postnatal growth of the rat lung. Anat Rec 180:77-98

29. Thurlbeck WM 1995 Lung growth and development. In: Thurlbeck WM, Churg AM (eds) Pathology of the Lung. Thieme Medical Publishers Inc, New York, pp 37-87

30. Veness-Meehan KA, Moats-Staats BM, Price WA, Stiles AD 1997 Re-emergence of a fetal pattern of insulin-like growth factor expression during hyperoxic rat lung injury. Am J Respir Cell Mol Biol 16:538-548

31. Thomas PS 1980 Hybridization of denatured RNA and small DNA fragments transferred to nitrocellulose. Proc Natl Acad Sci USA 77:5201-5205

32. Feinberg AP, Vogelstein B 1983 A technique for radiolabeling DNA restriction endonuclease fragments to high specific activity. Anal Biochem 132:6-13

33. Dawson-Saunders B, Trapp RG 1990 Basic and Clinical Biostatistics. Appelton \& Lange, Norwalk, CT, p 133-135

34. Cardoso WV, Williams MC, Mitsialis SA, Joyce-Brady M, Rishi AK, Brody JS 1995 Retinoic acid induces changes in the pattern of airway branching and alters epithelial cell differentiation in the developing lung in vitro. Am J Resp Cell Mol Biol $12: 464-476$

35. Cohen-Addad N, Bollinger R, Chou J, Poland R 1988 Vitamin A deficiency and pulmonary oxygen toxicity: morphometric studies in the murine lung. Pediatr Res 23:76-80

36. Shenai JP, Chytil F, Stahlman MT 1985 Vitamin A status of neonates with bronchopulmonary dysplasia. Pediatr Res 19:185-188

37. Hustead VA, Gutcher GR, Anderson S, Zachman RD 1985 Relationship of vitamin A (retinol) status to lung disease in the preterm infant. J Pediatr 105:610-615

38. Moreno-Manzano V, Rodriguez-Puyol M, Rodriguez-Puyol D, Lucio-Cazana FJ 1999 Tretinoin prevents age-related renal changes and stimulates antioxidant defenses in cultured renal mesangial cells. J Pharmacol Exp Ther 289:123-132

39. Kartha VNR, Krishnamurthy S 1977 Antioxidant function of vitamin A. Intern J Vit Nutr Res 47:394-401

40. Burri PH, Dbaly J, Weibel ER 1973 The postnatal growth of the rat lung. Anat Rec 178:711-730

41. Blanco LN, Massaro GD, Massaro D 1989 Alveolar dimensions and number: developmental and hormonal regulation. Am J Physiol 257:L240-L247

42. McMenamy KR, Anderson MJ, Zachman RD 1994 Effect of dexamethasone and oxygen exposure on neonatal rat lung retinoic acid receptor proteins. Ped Pulmonol 18:232-238

43. Crouch EC, Mecham RP, Davila RM, Noguchi A 1997 Collagens and elastic fiber proteins in lung development. Lung Biol Health Dis 100:327-364

44. Bienkowski RS, Cowan MJ, McDonald JA, Crystal RG 1978 Degradation of newly synthesized collagen. J Biol Chem 253:4356-4363

45. Laurent GJ 1987 Dynamic state of collagen: pathways of collagen degradation in vivo and their possible role in regulation of collagen mass. Am J Physiol 252:C1-C9

46. Haq RU, Pfahl M, Chytil F 1991 Retinoic acid affects the expression of nuclear retinoic acid receptors in tissues of retinol-deficient rats. Proc Natl Acad Sci USA $88: 8272-8276$

47. Petkovich M 1992 Regulation of gene expression by vitamin A: the role of nuclear retinoic acid receptors. Annu Rev Nutr 12:443-471

48. Chytil F, Haq RU 1990 Vitamin A mediated gene expression. Crit Rev Eukaryot Gene Expr 1:61-73

49. Bauer EA, Seltzer JL, Eisen Z 1983 Retinoic acid inhibition of collagenase and gelatinase expression in human skin fibroblast cultures. Evidence for a dual mechanism. J Invest Dermatol 81:162-169

50. Clark SD, Kobayashi DK, Welgus HG 1987 Regulation of the expression of tissue inhibitor of metalloproteinases and collagenase by retinoids and glucocorticoids in human fibroblasts. J Clin Invest 80:1280-1288 